\title{
Effect of Zirconium Oxide Nanofiller and Dibutyl Phthalate Plasticizer on Ionic Conductivity and Optical Properties of Solid Polymer Electrolyte
}

\author{
Siti Mariah Mohd Yasin, Suriani Ibrahim, and Mohd Rafie Johan \\ Nanomaterials Engineering Research Group, Advanced Materials Research Laboratory, Department of Mechanical Engineering, \\ University of Malaya, Lembah Pantai, 50603 Kuala Lumpur, Malaysia
}

Correspondence should be addressed to Mohd Rafie Johan; mrafiej@um.edu.my

Received 23 April 2014; Revised 17 June 2014; Accepted 26 June 2014; Published 15 July 2014

Academic Editor: Josias Hamman

Copyright (C) 2014 Siti Mariah Mohd Yasin et al. This is an open access article distributed under the Creative Commons Attribution License, which permits unrestricted use, distribution, and reproduction in any medium, provided the original work is properly cited.

New solid polymer electrolytes (SPE) based on poly(ethylene oxide) (PEO) doped with lithium trifluoromethanesulfonate $\left(\mathrm{LiCF}_{3} \mathrm{SO}_{3}\right)$, dibutyl phthalate (DBP) plasticizer, and zirconium oxide $\left(\mathrm{ZrO}_{2}\right)$ nanoparticles were prepared by solution-casting technique. The conductivity was enhanced by addition of dibutyl phthalate (DBP) plasticizer and $\mathrm{ZrO}_{2}$ nanofiller with maximum conductivity $\left(1.38 \times 10^{-4} \mathrm{Scm}^{-1}\right)$. The absorption edge and band gap values showed decreases upon addition of $\mathrm{LiSO}_{3} \mathrm{CF}_{3}, \mathrm{DBP}$, and $\mathrm{ZrO}_{2}$ due to the formation of localized states in the SPE and the degree of disorder in the films increased.

\section{Introduction}

Nowadays, the need for smaller, lighter, higher capacity, and energy density devices are tremendous especially in the field of polymer electrolytes materials. Extensive studies were conducted on solid polymer electrolytes (SPE) as new ionic conductors to replace the conventional electrolytic solutions [1]. It is believed that the electrolytic solutions have solution leakage, electrode corrosion, contamination, and solute seeping.

SPE based on poly(ethylene oxide) (PEO) have received much attention due to its well-dissolved salts and such electrolytes possess proper chemical structures to support the ion transport [2]. Many researchers discovered that these polymer electrolytes have low conductivities [3]. Nevertheless, they realized that polymer electrolytes have a big potential for future technology development. Since then, more investigations had been carried out to overcome the problem like the reduction of the PEO crystalline phase which is known to be contributed to its lower conductivity [4]. In that regard, addition of low molecular weight plasticizer into the polymer electrolytes systems will enhance the conductivity [5].
The plasticization is the conventional way to reduce the crystallinity and enhances the amorphous phase content of the polymer electrolytes. Thus, it increases the flexibility in the polymeric segments and produces mobile charge carriers due to ion dissolution effect. In this work, dibutyl phthalate (DBP) was used as a plasticizer. This leads to high ambient conductivity. DBP plasticizer contributed higher ionic conductivity compared to ethylene carbonate (EC) and polycarbonate (PC) plasticizers. For example at room temperature, electrolyte system with DBP [6] as a plasticizer contributes to $10^{-4} \mathrm{~S} / \mathrm{cm}$ compared to $\mathrm{EC} / \mathrm{PC}[7,8]$ with $10^{-6} \mathrm{~S} / \mathrm{cm}$.

However the conductivity enhancement occurred at the expense of SPE mechanical properties. To overcome this, the addition of nanosize ceramic fillers into the SPE system results in the increase of ionic conductivity coupled with its mechanical properties [9]. In this work, zirconium oxide $\left(\mathrm{ZrO}_{2}\right)$ nanoparticles were used as ceramic filler into the host polymer matrix $[10,11]$. The conductivity increases with decrease in particle size (nanometer), that is, increase in the ratio of surface area to volume, thus leading to an increasing dominance of the atomic behavior on the surface of particle compared to the dominance of the atomic behaviors in the 
interior of the particle. The larger surface area prevents the local polymer chain reorganization, leading to locking in high degree of disorder and enhancing the ionic conductivity. Moreover, the large surface area of $\mathrm{ZrO}_{2}$ nanoparticle results in a lot of interactions between the intermixed materials leading to special properties such as strength and increased chemical or heat resistance. Moreover, $\mathrm{ZrO}_{2}$ is the strongest and toughest ceramic material available for use in research and industrial area. It also offers potential for long-term stability. Filler will affect the polymer dipole orientation by their ability to align dipole moments. Addition of filler increases the ionic conductivity and mechanical stability of polymer electrolytes by inhibiting the recrystallization of polymer chains and providing $\mathrm{Li}^{+}$conducting pathways at the filler surface through Lewis acid-base interaction among different species in the electrolyte. The ion movement is obstructed by the crystalline region present in polymer electrolyte while blocking the paths of the ions. The amorphous region favors the conduction of $\mathrm{Li}^{+}$due to its greater free volume.

Optical study has been one of the most productive methods in understanding the band structure and energy gap of both crystalline and amorphous materials. In this light, the band structure of SPE will get affected due to the decrease of crystallinity as a result of adding plasticizer and filler. Studies on the ionic conduction is focusing on the nature of the charge transport that occurred in the polymer electrolyte while the optical properties are aimed at achieving better reflection, antireflection, interface, and polarization properties. The optical properties of polymers can be suitably modified by the addition of dopants depending on their reactivity with the host matrix. In our case, the dopants include the salt, plasticizer, and filler. We found that the doping elements are responsible for the formation of defects in the electrolyte film. By adding different element to the PEO complexes, optical band gap decreases for both direct and indirect transitions due to the compositional change in the host material. The decrease in the optical band gap results in an increase in the degree of disorder in the electrolyte films. As a result, the ionic conductivity of the film will be increased due to the increase of amorphous phase of the film. Therefore, ionic conductivity has a direct relationship with its optical property through their band gap energy.

Thus, the study on the effect of plasticizer and ceramic filler on $\mathrm{PEO} /$ salt based polymer electrolytes would be of great interest.

\section{Experiment}

Polymer electrolyte films were prepared using solutioncast technique. Polyethylene oxide (PEO, Aldrich) was used as host polymer matrix, lithium trifluoromethanesulfonate $\left(\mathrm{LiCF} \mathrm{SO}_{3}\right.$, Aldrich) as the salt for complexation, dibutyl phthalate (DBP, Alfa Aesar) as plasticizer and zirconium oxide $\left(\mathrm{ZrO}_{2}\right.$, Acros Organics) as nanoceramic filler. Prior to the preparation of polymer electrolyte, $\mathrm{LiCF}_{3} \mathrm{SO}_{3}$ was dried at $100^{\circ} \mathrm{C}$ for $1 \mathrm{~h}$ in order to eliminate trace amounts of water. $1 \mathrm{~g}$ of $\mathrm{PEO}$ (per mixture) and various wt.\% of $\mathrm{LiCF}_{3} \mathrm{SO}_{3}$ were dissolved separately in acetonitrile (Fisher) and these solutions were then mixed together and stirred. For the second system, different amounts of plasticizer (DBP) were added and stirred with the amount of polymer and salt being fixed. Finally, different amounts of ceramic filler $\left(\mathrm{ZrO}_{2}\right)$ were added and stirred with the amount of polymer, salt, and plasticizer being fixed. The solutions were stirred for $24 \mathrm{~h}$ and then were cast on petri dish and allowed to evaporate slowly inside a dessicator for about 4 days. All samples were stored under dry conditions.

Conductivity measurements were carried out using impedance spectroscopy HIOKI 3532 LCR Hi Tester, within the frequency range of $50 \mathrm{~Hz}$ to $1 \mathrm{MHz}$, with temperature ranging from room temperature to $373 \mathrm{~K}$. A specimen's area for all testing was $3.142 \mathrm{~cm}^{2}$ and the thickness range within $0.010-0.020 \mathrm{~cm}$. Optical studies were carried out using Cary 50 probe UV-visible spectrophotometer. The absorption spectra were analysed in a wavelength range of 190-800 nm.

\section{Result and Discussion}

3.1. Ionic Conductivity Study. Figure 1 shows the typical impedance plot of pure $\mathrm{PEO},\left(\mathrm{PEO} / \mathrm{LiCF}_{3} \mathrm{SO}_{3}\right)$, (PEO/ $\left.\mathrm{LiCF}_{3} \mathrm{SO}_{3} / \mathrm{DBP}\right)$, and $\left(\mathrm{PEO} / \mathrm{LiCF}_{3} \mathrm{SO}_{3} / \mathrm{DBP} / \mathrm{ZrO}_{2}\right)$ at room temperature in the frequency range of $50 \mathrm{~Hz}$ to $5 \mathrm{MHz}$. The Cole-Cole plots of the films are consisting of a semicircular arc and inclined spike, both representing behaviour of ionically conducting solid electrolyte films with blocking electrode [12].

Figure 1(a) shows the semicircle arc due to the parallel combination of bulk resistance and bulk capacitance. The bulk resistance is due to the migration of ion and the bulk capacitance is due to the immobile polymer chains [13]. Figures 1(b)-1(d) show the inclination of the spike that have an angle less than $90^{\circ}$ to the real axis due to the roughness of the electrode-electrolyte interface [14]. The inclined spikes indicate the double layer capacitance formed at the electrode-electrolyte interface because of ionic migration at low frequency. When the frequency decreases, the impedance against ion transfer increases, which is represented by the electrode double layer at each interface [15].

The ionic conductivity of the sample can be obtained using the equation below:

$$
\sigma=\frac{t}{R_{b} A}
$$

where $\sigma$ is the conductivity, $t(\mathrm{~cm})$ is the thickness of the sample, $R_{b}(\Omega)$ is the bulk resistance, and $A\left(\mathrm{~cm}^{2}\right)$ is the area of the electrode and electrolyte contact. The $R_{b}$ value is obtained from the intercept of Cole-Cole plot with $x$-axis. Table 1 summarized the conductivity values of SPE calculated using (1). It shows that sample with $0.05 \mathrm{wt} . \% \mathrm{ZrO}_{2}$ possesses the highest ionic conductivity.

Figure 2 shows the conductivity of $\mathrm{PEO}+\mathrm{LiSO}_{3} \mathrm{CF}_{3}$ with different wt.\% of $\mathrm{LiSO}_{3} \mathrm{CF}_{3}$. The amount of salt was varied from 4 to 16 wt. $\%$ of $\mathrm{LiSO}_{3} \mathrm{CF}_{3}$. The highest conductivity of $\mathrm{PEO}+\mathrm{LiSO}_{3} \mathrm{CF}_{3}$ system was obtained at $14 \mathrm{wt} . \%$ of $\mathrm{LiCF}_{3} \mathrm{SO}_{3}$, which is $9.24 \times 10^{-6} \mathrm{Scm}^{-1}$. Beyond $14 \mathrm{wt} . \%$ of $\mathrm{LiSO}_{3} \mathrm{CF}_{3}$, the sample was sticky and difficult to pry out from the petri dish. Hence, the sample failed to form film and 


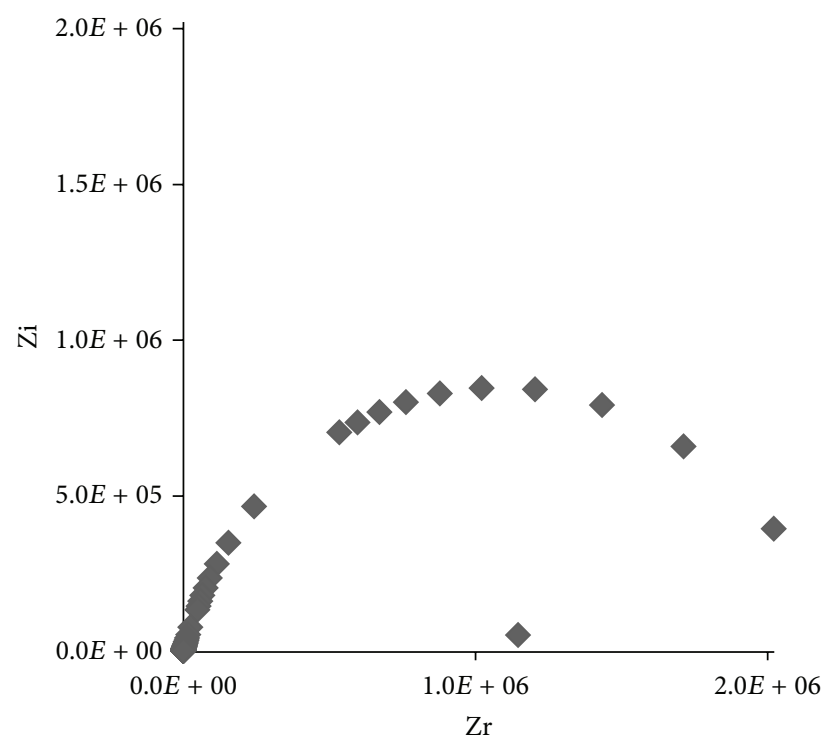

(a)

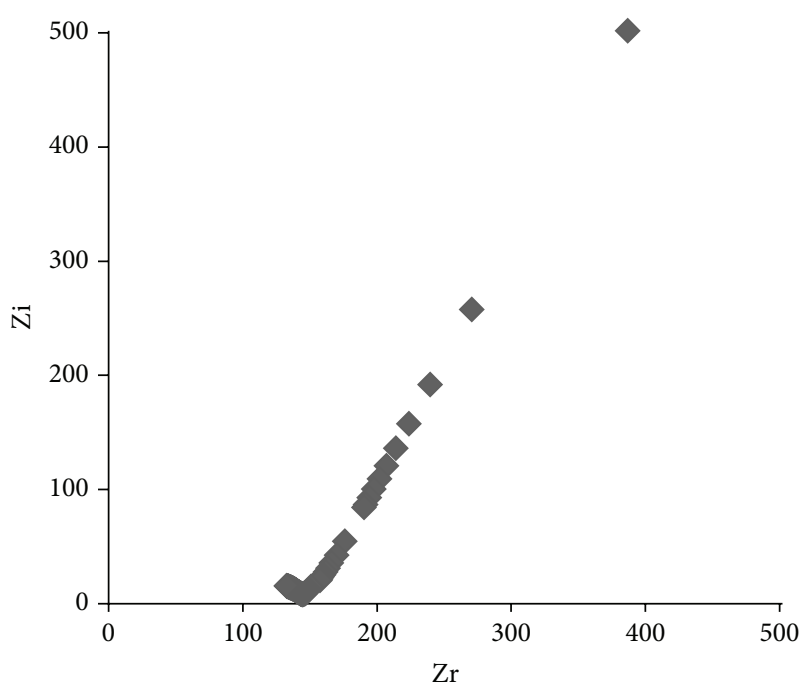

(c)

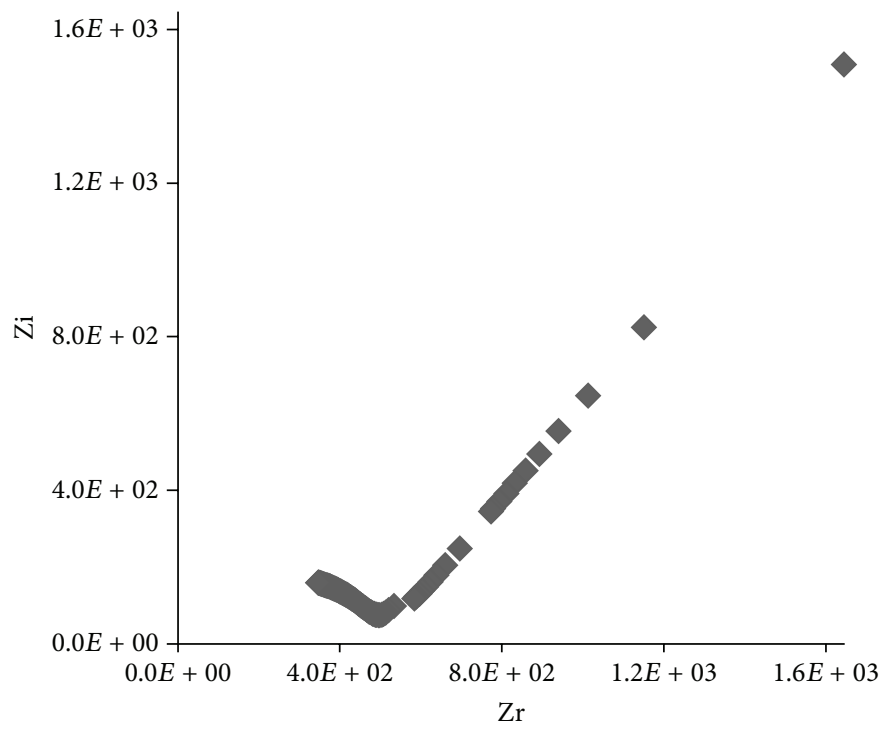

(b)

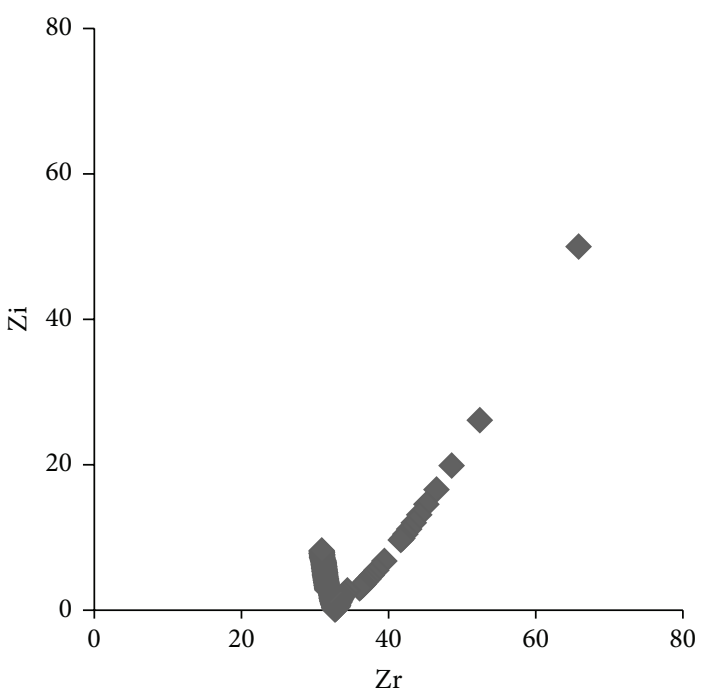

(d)

Figure 1: Cole-Cole plot for SPE samples: (a) PEO; (b) $\left(\mathrm{PEO} / \mathrm{LiCF}_{3} \mathrm{SO}_{3}\right)$; (c) $\left(\mathrm{PEO} / \mathrm{LiCF}_{3} \mathrm{SO}_{3} / \mathrm{DBP}\right)$; (d) $\left(\mathrm{PEO} / \mathrm{LiCF}_{3} \mathrm{SO}_{3} / \mathrm{DBP} / \mathrm{ZrO}{ }_{2}\right.$ ) at ambient temperature.

remained permanently in a gel-like state. The inset in Figure 2 shows that intercept on the $Z_{r}$ axis was attributed to the bulk resistance.

It is evident from Figure 2 that for different electrolyte films with various concentration of $\mathrm{LiCF}_{3} \mathrm{SO}_{3}$, their ionic conductivity increases to higher value with increasing of lithium ions due to the increase of charge carriers to the polymer electrolyte [16]. Besides that, the increase of conductivity is also attributed to the reduction in crystallinity of polymer electrolyte. The motion of lithium ions in this solid electrolyte is a liquid-like property. Therefore, the ionic movement through the SPE is facilitated by the large amplitude of the polymer segmental motion [17].

Figure 3 shows the variation in conductivity for PEO + $\mathrm{LiSO}_{3} \mathrm{CF}_{3}$ with different wt.\% of DBP. The conductivity showed a maximum value at $1.0 \mathrm{wt} . \%$ of DBP $(4.51 \times$ $10^{-5} \mathrm{Scm}^{-1}$ ) as shown in the inset of the figure. DBP appears to play a catalytic role in dissociating the salt and increasing the carrier concentration [3]. DBP increased the dissociation of $\mathrm{LiCF}_{3} \mathrm{SO}_{3}$ into $\mathrm{Li}^{+}$and $\mathrm{CF}_{3} \mathrm{SO}_{3}{ }^{-}$ions up to $1.0 \mathrm{wt}$.\% of DBP. The value of conductivity decreases beyond $1.0 \mathrm{wt} . \%$ of DBP due to the diluents effect of DBP which lowers the number of $\mathrm{Li}^{+}$ions per unit volume [1]. This could be ascribed to ion aggregation and, as a result, decreases the available charge carriers. The films also became sticky in nature [18].

The Cole-Cole plot for the highest conductivity of PEO + $\mathrm{LiCF}_{3} \mathrm{SO}_{3}+\mathrm{DBP}+\mathrm{ZrO}_{2}$ film is shown (inset) in Figure 4 . It is observed that the conductivity in filler system is higher than that in other systems. The maximum conductivity $(1.38 \times$ $10^{-4} \mathrm{Scm}^{-1}$ ) was obtained for samples PEO + $14 \mathrm{wt} . \%$ 


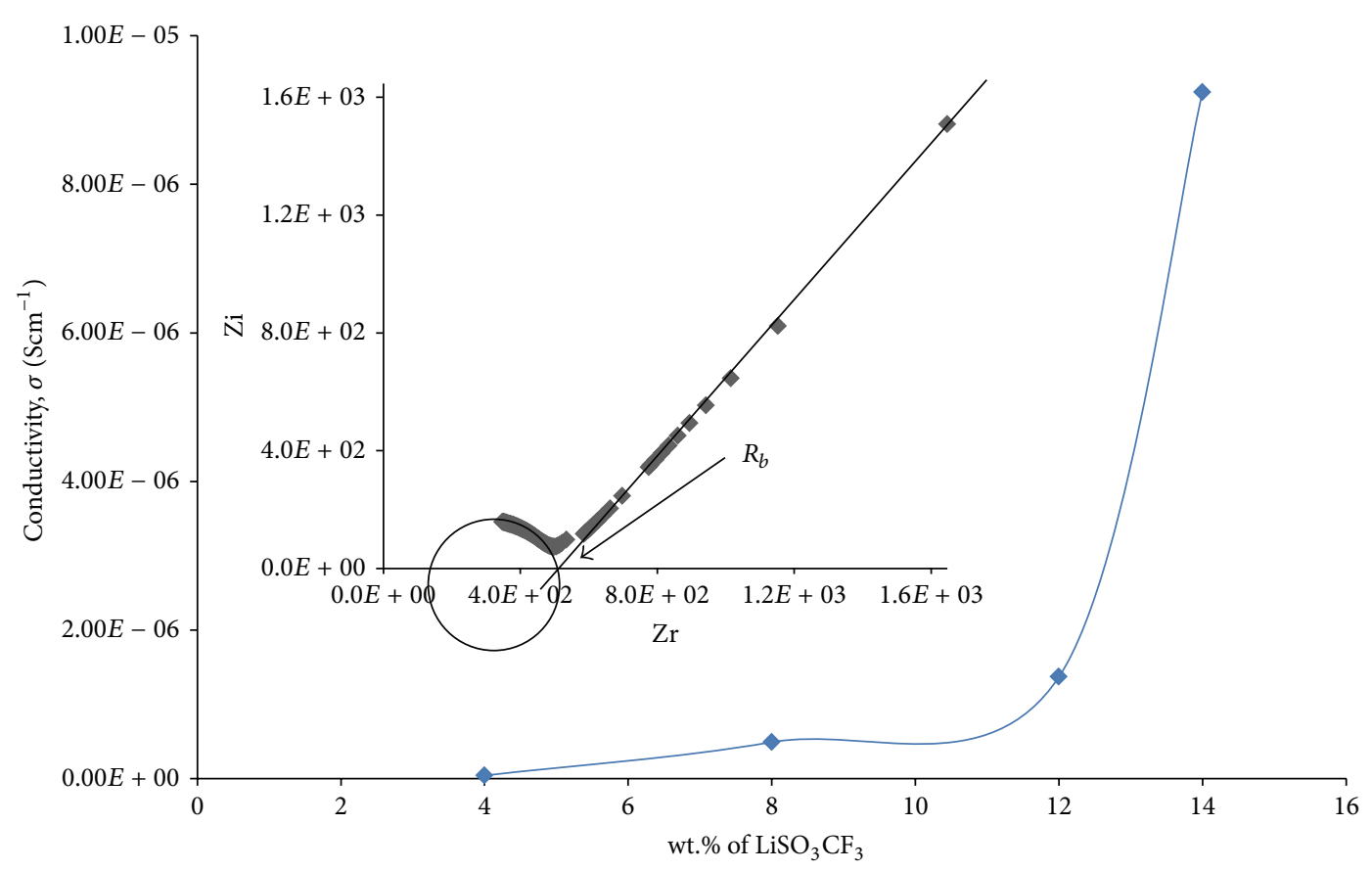

FIGURE 2: Ionic conductivities of SPE for various wt. $\%$ of $\mathrm{LiSO}_{3} \mathrm{CF}_{3}$ and impedance plot for sample with the highest conductivity (inset).

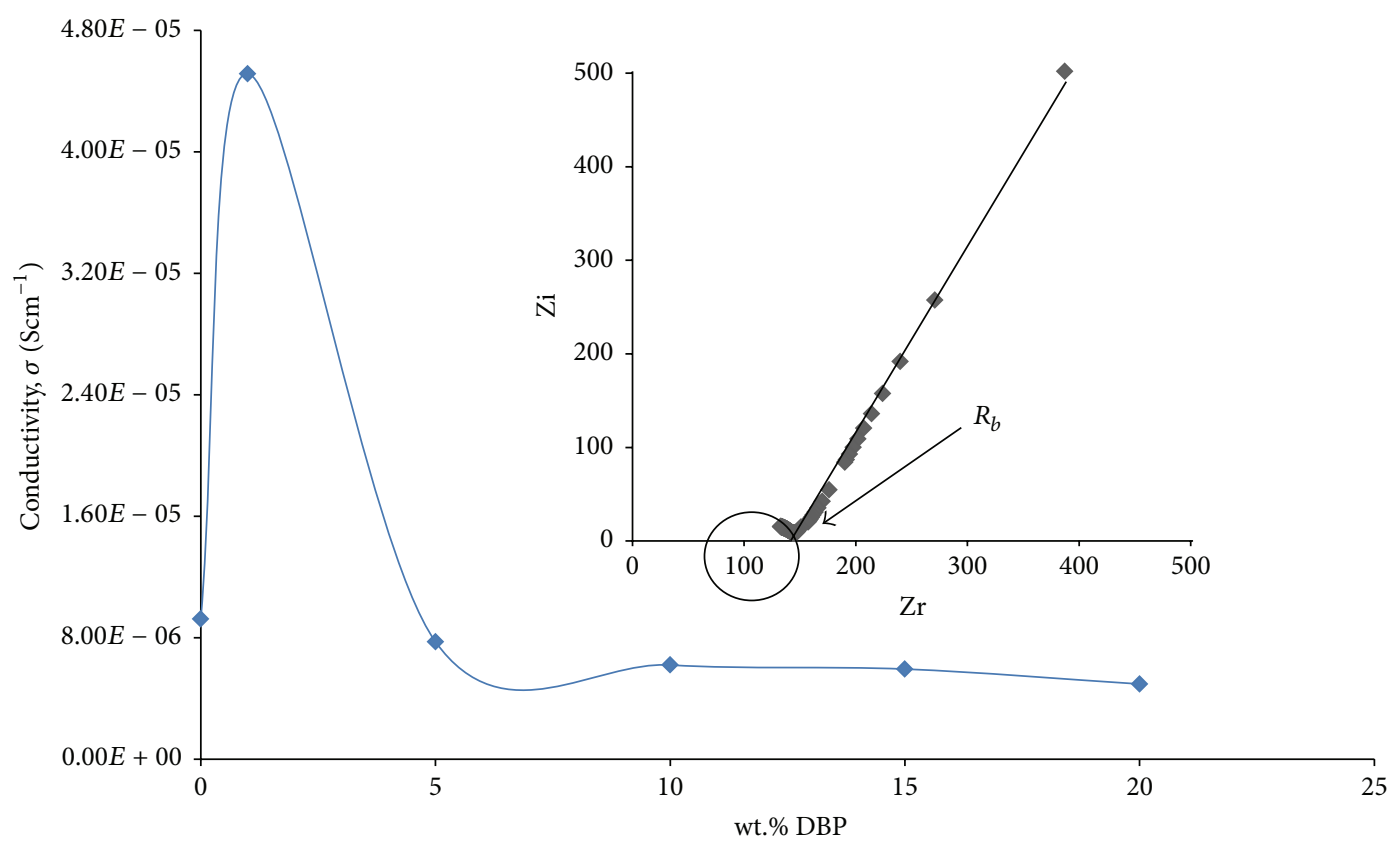

FIGURE 3: Ionic conductivities of SPE for various wt.\% of DBP and impedance plot for sample with the highest conductivity (inset).

$\mathrm{LiCF}_{3} \mathrm{SO}_{3}+1$ wt. $\% \mathrm{DBP}+0.05$ wt. $\% \mathrm{ZrO}_{2}$. However, the ionic conductivity does not continually rise indefinitely and declines beyond $0.05 \mathrm{wt}$. $\%$ of $\mathrm{ZrO}_{2}$. This could be ascribed to the fact that filler grains get close enough to each other as the filler concentration is further increased. The blocking effect or geometrical constrictions imposed by more abundant zirconia grains leading to long polymer chains become more "immobilized." Consequently, the conductivity drops after reaching the maximum [19]. The addition of lower wt.\% of filler into the SPE system slightly enhances the conductivity. This promotes structural modification of the polymer chains and thereby increases the fraction of the amorphous phase present at lower temperature [20]. Consequently, this favours $\mathrm{Li}^{+}$ion migration. The mechanism of conductivity enhancement in SPE due to ceramic additives remains uncertain until present, although several models have been discovered [21]. 


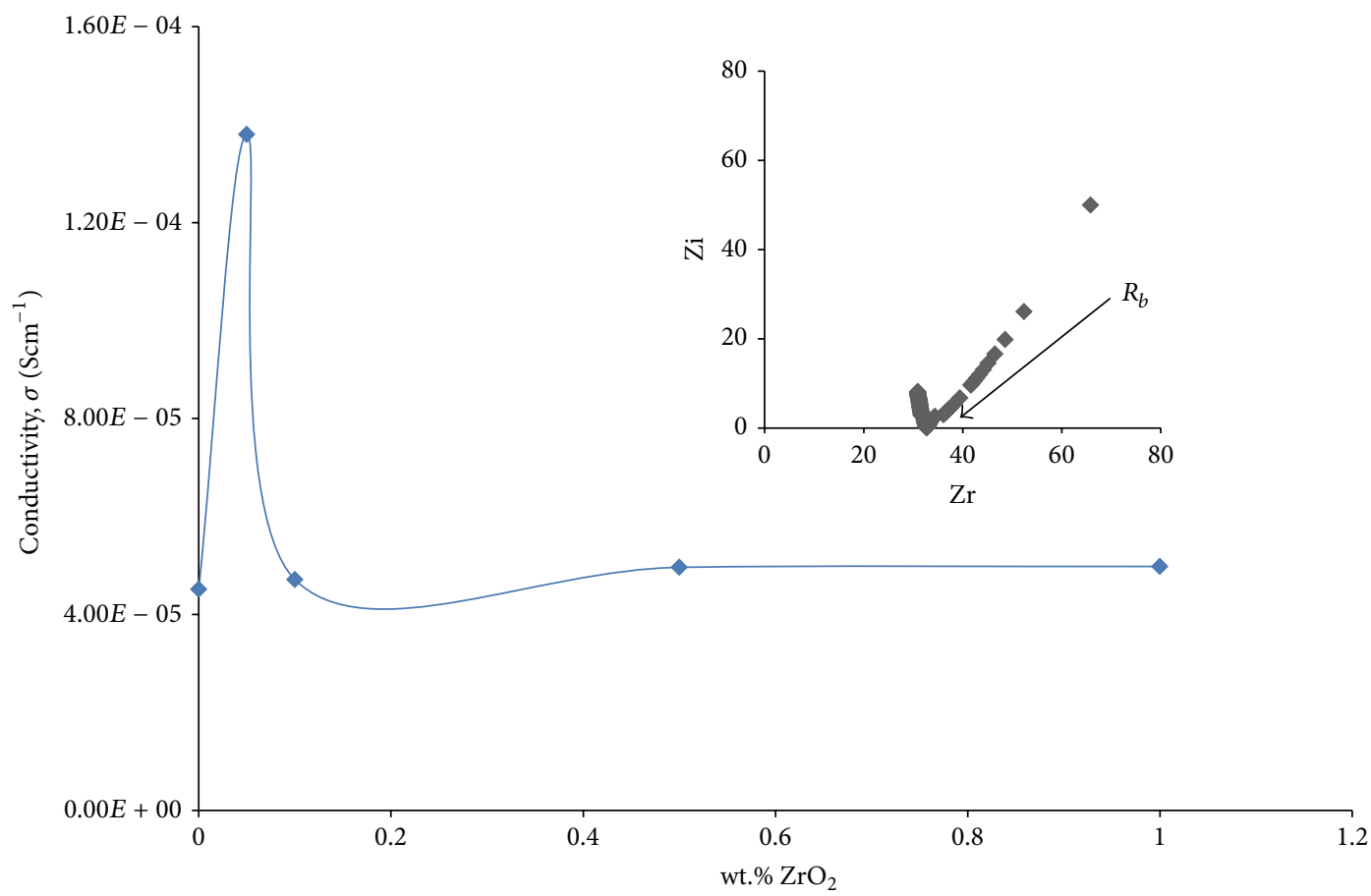

FIGURE 4: Ionic conductivities of SPE for various wt.\% of $\mathrm{ZrO}_{2}$ nanofiller and impedance plot for sample with the highest conductivity (inset).

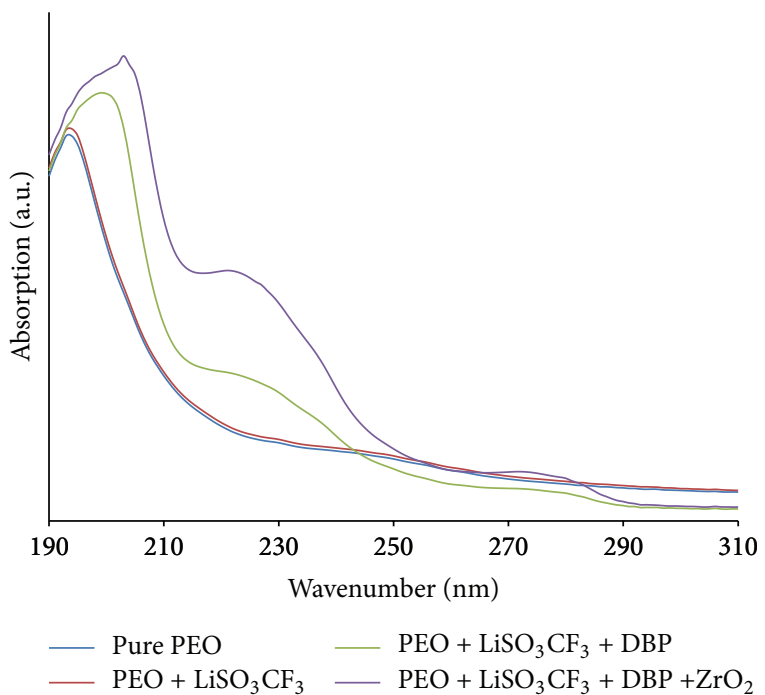

FIGURE 5: Optical absorption spectra for SPE for various wt.\% of $\mathrm{ZrO}_{2}$ nanofiller.

However, the discovered mechanism is that ceramic additives reduce the host polymer crystallinity which, in turn, enhances the conductivity.

3.2. Optical Study. Figure 5 shows the absorption spectra for pure and salted SPE around 197-204 $\mathrm{nm}$. The bands exhibit different intensities and are assigned to the $n \rightarrow \sigma^{*}$ transition from nonbonding to sigma antibonding orbitals. This transition usually comes from saturated compound
TABLE 1: Conductivity values of SPE at ambient temperature.

\begin{tabular}{|c|c|}
\hline Sample & $\begin{array}{c}\text { Conductivity } \sigma \\
\left(\mathrm{Scm}^{-1}\right)\end{array}$ \\
\hline PEO & $1.58 \times 10^{-9}$ \\
\hline $\mathrm{PEO}+4$ wt. $\% \mathrm{LiCF}_{3} \mathrm{SO}_{3}$ & $4.17 \times 10^{-8}$ \\
\hline $\mathrm{PEO}+8$ wt. $\% \mathrm{LiCF}_{3} \mathrm{SO}_{3}$ & $4.91 \times 10^{-7}$ \\
\hline $\mathrm{PEO}+12$ wt. $\% \mathrm{LiCF}_{3} \mathrm{SO}_{3}$ & $1.37 \times 10^{-6}$ \\
\hline $\mathrm{PEO}+14$ wt. $\% \mathrm{LiCF}_{3} \mathrm{SO}_{3}$ & $9.24 \times 10^{-6}$ \\
\hline $\mathrm{PEO}+14$ wt. $\% \mathrm{LiCF}_{3} \mathrm{SO}_{3}+1 \mathrm{wt} . \% \mathrm{DBP}$ & $4.51 \times 10^{-5}$ \\
\hline $\mathrm{PEO}+14$ wt. $\% \mathrm{LiCF}_{3} \mathrm{SO}_{3}+5$ wt. $\%$ DBP & $4.96 \times 10^{-6}$ \\
\hline $\mathrm{PEO}+14$ wt. $\% \mathrm{LiCF}_{3} \mathrm{SO}_{3}+10$ wt. $\%$ DBP & $5.94 \times 10^{-6}$ \\
\hline $\mathrm{PEO}+14$ wt. $\% \mathrm{LiCF}_{3} \mathrm{SO}_{3}+15$ wt. $\%$ DBP & $6.20 \times 10^{-6}$ \\
\hline $\mathrm{PEO}+14$ wt. $\% \mathrm{LiCF}_{3} \mathrm{SO}_{3}+20$ wt. $\%$ DBP & $7.73 \times 10^{-6}$ \\
\hline $\begin{array}{l}\mathrm{PEO}+14 \text { wt. } \% \mathrm{LiCF}_{3} \mathrm{SO}_{3}+1 \text { wt. } \% \text { DBP } \\
+0.05 \text { wt. } \% \mathrm{ZrO}_{2}\end{array}$ & $1.38 \times 10^{-4}$ \\
\hline $\begin{array}{l}\mathrm{PEO}+14 \text { wt. } \% \mathrm{LiCF}_{3} \mathrm{SO}_{3}+1 \text { wt. } \% \text { DBP } \\
+0.10 \text { wt. } \% \mathrm{ZrO}_{2}\end{array}$ & $4.71 \times 10^{-5}$ \\
\hline $\begin{array}{l}\mathrm{PEO}+14 \text { wt. } \% \mathrm{LiCF}_{3} \mathrm{SO}_{3}+1 \text { wt. } \% \mathrm{DBP} \\
+0.50 \text { wt. } \% \mathrm{ZrO}_{2}\end{array}$ & $4.96 \times 10^{-5}$ \\
\hline $\begin{array}{l}\mathrm{PEO}+14 \text { wt. } \% \mathrm{LiCF}_{3} \mathrm{SO}_{3}+1 \text { wt. } \% \text { DBP } \\
+1.00 \text { wt. } \% \mathrm{ZrO}^{2}\end{array}$ & $4.98 \times 10^{-5}$ \\
\hline
\end{tabular}

containing atoms with nonbonding orbital, that is, a lone pair on oxygen, such as $\mathrm{C}-\mathrm{O}$ bond in the polymer chain, whereas, the plasticized and filler added SPE were observed at around 218-237 $\mathrm{nm}$. These may be attributed to the $\pi \rightarrow \pi^{*}$, which is the promotion of an electron from pi bonding orbital to pi antibonding orbital. The small peaks at around $270-289 \mathrm{~nm}$ 


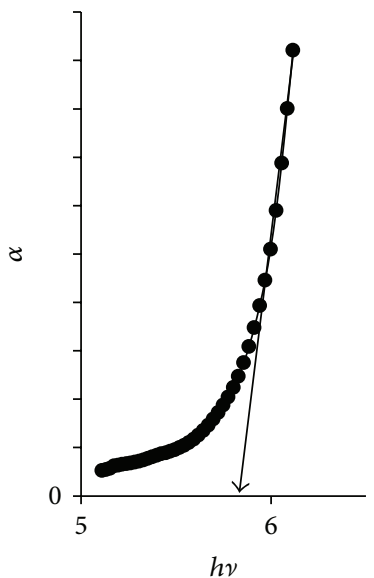

(A)

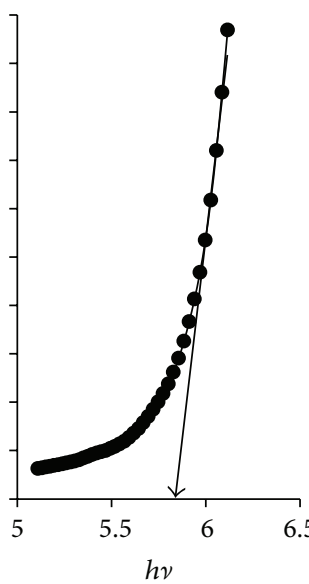

(B)

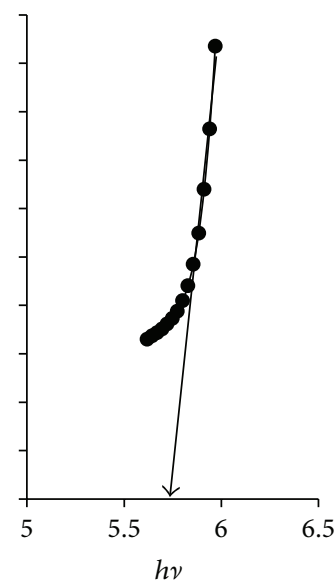

(C)

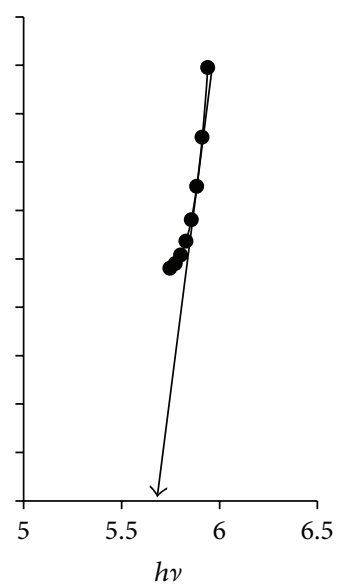

(D)

(a)

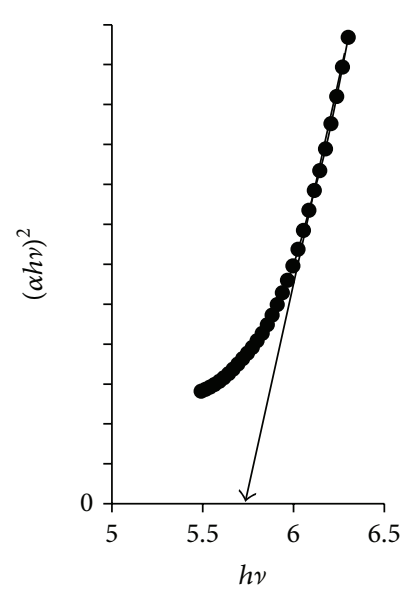

(A)

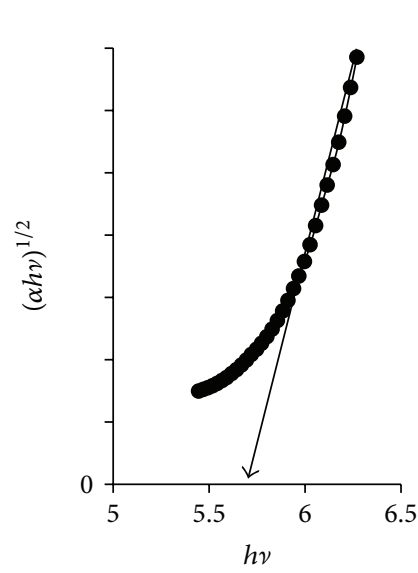

(A)

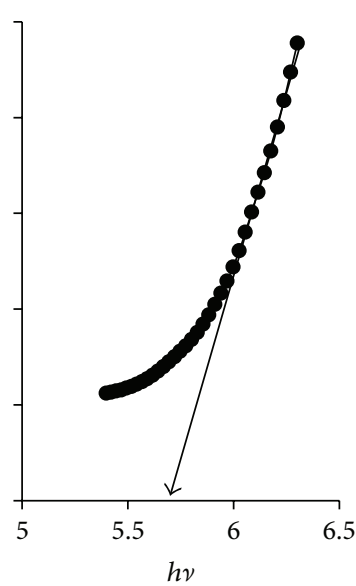

(B)

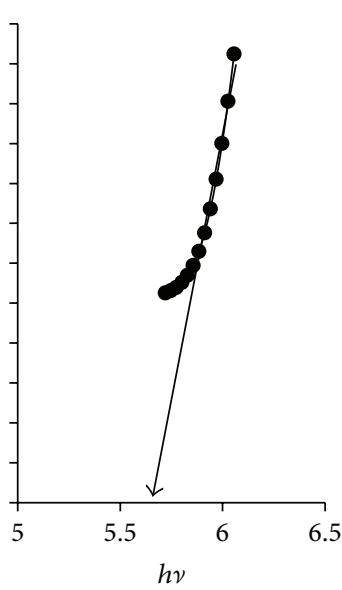

(C)

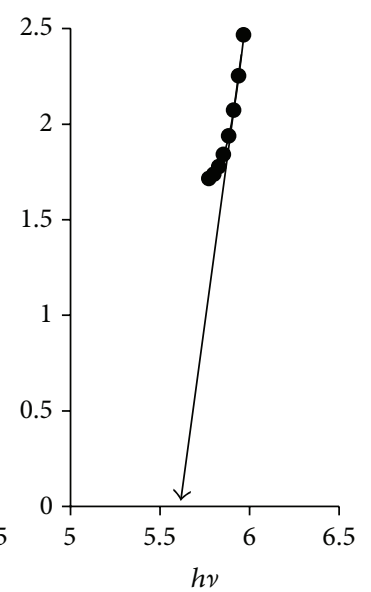

(D)

(b)

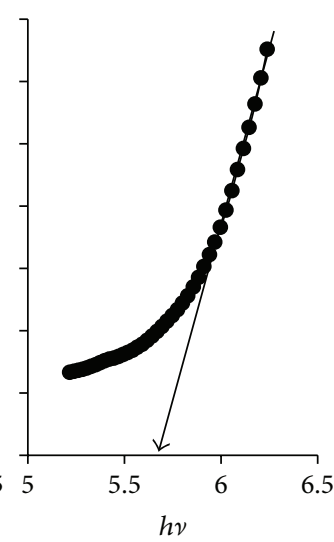

(B)

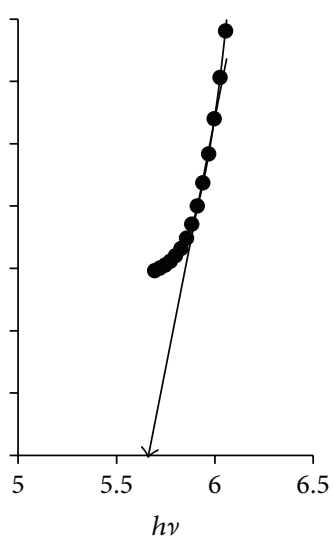

(C)

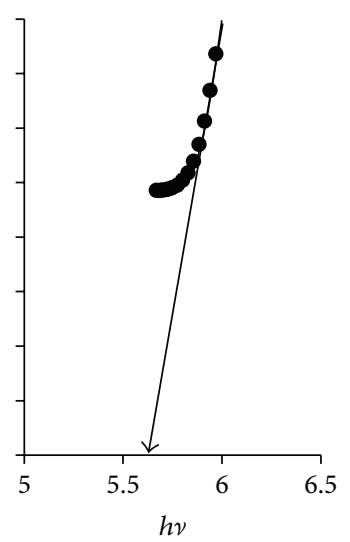

(D)

(c)

Figure 6: (a) Plot of $\alpha$ versus $h v$ (photon energy); (b) plot of $(\alpha h v)^{2}$ versus $h v$ (direct band gap); (c) plot of $(\alpha h v)^{1 / 2}$ versus $h v$ (indirect band gap) for (A) pure PEO; (B) PEO and $\mathrm{LiSO}_{3} \mathrm{CF}_{3}$; (C) PEO and $\mathrm{LiSO}_{3} \mathrm{CF}_{3}$ and DBP; (D) PEO and $\mathrm{LiSO}_{3} \mathrm{CF}_{3}$ and $\mathrm{DBP}+\mathrm{ZrO}$. 
TABLE 2: Absorption edge and band gaps values for SPE.

\begin{tabular}{|c|c|c|c|}
\hline \multirow{2}{*}{ Polymer electrolyte } & \multirow{2}{*}{$\begin{array}{l}\text { Absorption } \\
\text { edge }(\mathrm{eV})\end{array}$} & \multicolumn{2}{|c|}{ Band gap (eV) } \\
\hline & & Direct & Indirect \\
\hline Pure PEO & 5.80 & 5.70 & 5.68 \\
\hline $\mathrm{PEO}+14$ wt. $\% \mathrm{LiCF}_{3} \mathrm{SO}_{3}$ & 5.78 & 5.68 & 5.65 \\
\hline $\begin{array}{l}\mathrm{PEO}+14 \text { wt. } \% \mathrm{LiCF}_{3} \mathrm{SO}_{3} \\
+1 \text { wt. } \% \text { DBP }\end{array}$ & 5.70 & 5.65 & 5.53 \\
\hline $\begin{array}{l}\mathrm{PEO}+14 \text { wt. } \% \mathrm{LiCF}_{3} \mathrm{SO}_{3} \\
+1 \text { wt. } \% \text { DBP + } 0.05 \text { wt. } \% \mathrm{ZrO}_{2}\end{array}$ & 5.68 & 5.60 & 5.57 \\
\hline
\end{tabular}

were observed for both plasticized and filler systems can be assigned to the $n \rightarrow \pi^{*}$, which is promotion of an electron from nonbonding orbital to pi antibonding orbital. These transitions for both electrolyte systems need an unsaturated group in the molecule to provide the $\mathrm{p}$ electrons for the $\mathrm{C}=\mathrm{O}$ bond in the plasticizer and filler molecules [22].

Figure 6 shows the optical band gap of SPE (maximum conductivity) based on the Tauc plot equation for direct and indirect transitions [23]:

$$
\begin{gathered}
(\alpha h v)=\beta_{2}\left(h v-E_{\mathrm{gd}}\right)^{2} \\
(\alpha h v)=\beta_{1}\left(h v-E_{\mathrm{gi}}\right)^{1 / 2} .
\end{gathered}
$$

Here $h v$ is the photon energy, $E_{\mathrm{gd}}$ is the direct band gap, $E_{\mathrm{gi}}$ is the indirect band gap, $\alpha$ represents the absorption coefficient, and $\beta_{1}$ and $\beta_{2}$ are the constants equal to $\left(4 \pi \sigma_{o} / n c \Delta E\right)$ whereby $n$ is the refractive index.

The absorption edge values were obtained by extrapolating the linear portions of $\alpha$ versus $h v$ curves to zero absorption values, as shown in Figure 6(a). When a direct band gap exists, the absorption coefficient of electron transition depends on the energy of incident photon according to (2).

The direct band gap values were obtained from the plots of $(\alpha h v)^{2}$ versus $h v$ and the allowed direct transition energies were determined by the intercept on the energy axis, on extrapolating the linear portion of the curves to zero absorption value as shown in Figure 6(b). For indirect electron transitions $(\alpha h v)^{1 / 2}$ versus $h v$ as shown in Figure 6(c) which require photon assistance, the absorption coefficient has the following dependence on photon energy according to (3).

The values of absorption edge, direct band gap, and indirect band gap are shown in Table 2. It is clear that all values showed a decrease upon doping with salt $\mathrm{LiSO}_{3} \mathrm{CF}_{3}$, plasticizer DBP, and filler $\mathrm{ZrO}_{2}$. They are responsible for the defect formation in the electrolytes which produced the localized states in the optical band gap. Thus, this state was responsible for decreasing energy band gap.

\section{Conclusion}

Nanocomposite SPE have been successfully prepared by solution casting technique. The incorporation of $\mathrm{LiCF}_{3} \mathrm{SO}_{3}$ salt, DBP plasticizer, and $\mathrm{ZrO}_{2}$ nanofiller has led to significantly enhanced ionic conductivities. The composition of PEO + $\mathrm{LiCF}_{3} \mathrm{SO}_{3}+\mathrm{DBP}+0.05 \mathrm{wt} . \% \mathrm{ZrO}_{2}$ exhibits the highest conductivity, $\left(1.38 \times 10^{-4} \mathrm{Scm}^{-1}\right)$, compared with the conductivity of pure PEO $\left(1.58 \times 10^{-9} \mathrm{Scm}^{-1}\right)$ and $\mathrm{PEO}+\mathrm{LiCF}_{3} \mathrm{SO}_{3}$ $\left(9.24 \times 10^{-6} \mathrm{Scm}^{-1}\right)$. As the salt $\left(\mathrm{LiSO}_{3} \mathrm{CF}_{3}\right)$ content increases, the conductivity increases because the density of mobile ions increases and, therefore, the polymer segment's motion is promoted. The incorporation of plasticizer (DBP) into the polymer electrolytes increases 4 orders of magnitude. It generally results from the reduction of crystallinity, the increase of salt dissociation capability, and the rise of charge carrier diffusions. However, the increase of conductivity of polymer electrolyte due to the plasticizer is coupled with a decrease in its mechanical strength. The incorporation of ceramic nanofiller seems to be an alternative provider of higher conductivity, cationic transference number, and mechanical strength. These three elements, salt, plasticizer, and nanosize filler, are mutually combined and connect towards formation of the superior solid polymer electrolyte. Each element (salt, plasticizer, and filler) is important and plays its specific role towards the formation of polymer electrolyte. It is very difficult to choose which one is more important since each contributes in their own way. Optical analysis of absorption edge, direct band gap, and indirect band gap values showed a decrease upon doping with $\mathrm{LiSO}_{3} \mathrm{CF}_{3}, \mathrm{DBP}$, and $\mathrm{ZrO}_{2}$ to the pure PEO film. This incorporation was responsible for the formation of defects in the electrolytes. This produced the localized states in the SPE and the degree of disorder in the films increased.

\section{Conflict of Interests}

The authors declare that there is no conflict of interests regarding the publication of this paper.

\section{Acknowledgments}

The authors greatly appreciate the financial support funded by the Ministry of Higher Education Malaysia and University of Malaya through High Impact Research Grant (UM.C/625/1/HIR/MOHE/ENG12).

\section{References}

[1] T. Kuila, H. Acharya, S. K. Srivastava, B. K. Samantaray, and S. Kureti, "Enhancing the ionic conductivity of PEO based plasticized composite polymer electrolyte by $\mathrm{LaMnO}_{3}$ nanofiller," Materials Science and Engineering B, vol. 137, no. 1-3, pp. 217224, 2007.

[2] H. M. J. C. Pitawala, M. A. K. L. Dissanayake, and V. A. Seneviratne, "Combined effect of $\mathrm{Al}_{2} \mathrm{O}_{3}$ nano-fillers and EC plasticizer on ionic conductivity enhancement in the solid polymer electrolyte (PEO) ${ }_{9}$ LiTf," Solid State Ionics, vol. 178, no. 13-14, pp. 885-888, 2007.

[3] A. M. Sukeshini, A. R. Kulkarni, and A. Sharma, "PEO based solid polymer electrolyte plasticized by dibutyl phthalate," Solid State Ionics, vol. 113-115, pp. 179-186, 1998.

[4] M. R. Johan and L. B. Fen, "Combined effect of $\mathrm{CuO}$ nanofillers and DBP plasticizer on ionic conductivity enhancement in the solid polymer electrolyte PEO- $\mathrm{LiCF}_{3} \mathrm{SO}_{3}$," Ionics, vol. 16, no. 4, pp. 335-338, 2010. 
[5] S. M. Tan and M. R. Johan, "Effects of $\mathrm{MnO}_{2}$ nano-particles on the conductivity of PMMA-PEO- $\mathrm{LiClO}_{4}$-EC polymer electroytes," Ionics, vol. 17, p. 147, 2011.

[6] A. M. Sukeshini, A. Nishimoto, and M. Watanabe, "Transport and electrochemical characterization of plasticized poly(vinyl chloride) solid electrolytes," Solid State Ionics, vol. 86-88, no. 1, pp. 385-393, 1996.

[7] S. Ramesh and A. K. Arof, "Electrical conductivity studies of polyvinyl chloride-based electrolytes with double salt system," Solid State Ionics, vol. 136-137, pp. 1197-1200, 2000.

[8] S. Ramesh and A. K. Arof, "Ionic conductivity studies of plasticized poly(vinyl chloride) polymer electrolytes," Materials Science and Engineering B: Solid-State Materials for Advanced Technology, vol. 85, no. 1, pp. 11-15, 2001.

[9] M. A. K. L. Dissanayake, P. A. R. D. Jayathilaka, R. S. P. Bokalawala, I. Albinsson, and B.-E. Mellander, "Effect of concentration and grain size of alumina filler on the ionic conductivity enhancement of the $(\mathrm{PEO})_{9} \mathrm{LiCF}_{3} \mathrm{SO}_{3}: \mathrm{Al}_{2} \mathrm{O}_{3}$ composite polymer electrolyte," Journal of Power Sources, vol. 119-121, pp. 409-414, 2003.

[10] T. Otsuka and Y. Chujo, "Poly(methyl methacrylate) (PMMA)based hybrid materials with reactive zirconium oxide nanocrystals," Polymer Journal, vol. 42, no. 1, pp. 58-65, 2010.

[11] C. J. Leo, G. V. Subba Rao, and B. V. R. Chowdari, "Studies on plasticized PEO-lithium triflate-ceramic filler composite electrolyte system," Solid State Ionics, vol. 148, no. 1-2, pp. 159$171,2002$.

[12] A. Kennelly, "Impedance," Transaction of the American Institute of Electrical Engineers, pp. 172-232, 1893.

[13] K. Kiran Kumar, M. Ravi, Y. Pavani, S. Bhavani, A. K. Sharma, and V. V. R. Narasimha Rao, "Investigations on the effect of complexation of $\mathrm{NaF}$ salt with polymer blend (PEO/PVP) electrolytes on ionic conductivity and optical energy band gaps," Physica B: Condensed Matter, vol. 406, no. 9, pp. 1706-1712, 2011.

[14] C. S. Ramya, S. Selvasekarapandian, G. Hirankumar, T. Savitha, and P. C. Angelo, "Investigation on dielectric relaxations of PVP-NH4SCN polymer electrolyte," Journal of Non-Crystalline Solids, vol. 354, no. 14, pp. 1494-1502, 2008.

[15] X. Li and S. L. Hsu, "An analysis of the crystallization behavior of poly(ethylene oxide)/poly(methyl methacrylate) blends by spectroscopic and calorimetric techniques," Journal of Polymer Science Part B: Polymer Physics, vol. 22, no. 7, pp. 1331-1342, 1984.

[16] W. Hou, C. Chen, C. Wang, and Y. Huang, "The effect of different lithium salts on conductivity of comb-like polymer electrolyte with chelating functional group," Electrochimica Acta, vol. 48, no. 6, pp. 679-690, 2003.

[17] V. M. Mohan, V. Raja, A. K. Sharma, and V. V. R. NarasimhaRao, "Ionic conductivity and discharge characteristics of solid-state battery based on novel polymer electrolyte $\left(\mathrm{PEO}+\mathrm{NaBiF}_{4}\right)$," Materials Chemistry and Physics, vol. 94, pp. 177-181, 2006.

[18] M. Kumar and S. S. Sekhon, "Role of plasticizer's dielectric constant on conductivity modification of $\mathrm{PEO}-\mathrm{NH}_{4} \mathrm{~F}$ polymer electrolytes," European Polymer Journal, vol. 38, no. 7, pp. 12971304, 2001.

[19] M. Z. A. Yahya and A. K. Arof, "Effect of oleic acid plasticizer on chitosan-lithium acetate solid polymer electrolytes," European Polymer Journal, vol. 39, no. 5, pp. 897-902, 2003.

[20] M. S. Michael, M. M. E. Jacob, S. R. S. Prabaharan, and S. Radhakrishna, "Enhanced lithium ion transport in PEObased solid polymer electrolytes employing a novel class of plasticizers," Solid State Ionics, vol. 98, no. 3-4, pp. 167-174, 1997.
[21] S. Slane and M. Salomon, "Composite polymer electrolyte for lithium batteries," Technical Report Apr-TR-426, US Army Research Laboratory, Oceanport, NJ, USA, 1995.

[22] K. K. Kumar, M. Ravi, Y. Pavani, S. Bhavani, A. K. Sharma, and V. V. R. N. Rao, "Investigations on the effect of complexation of $\mathrm{NaF}$ salt with polymer blend (PEO/PVP) electrolytes on ionic conductivity and optical energy band gaps," Physica B: Condensed Matter, vol. 406, no. 9, pp. 1706-1712, 2011.

[23] D. S. Davis and T. S. Shalliday, "Some optical properties of cadmium telluride," Physical Review, vol. 118, p. 1020, 1960. 

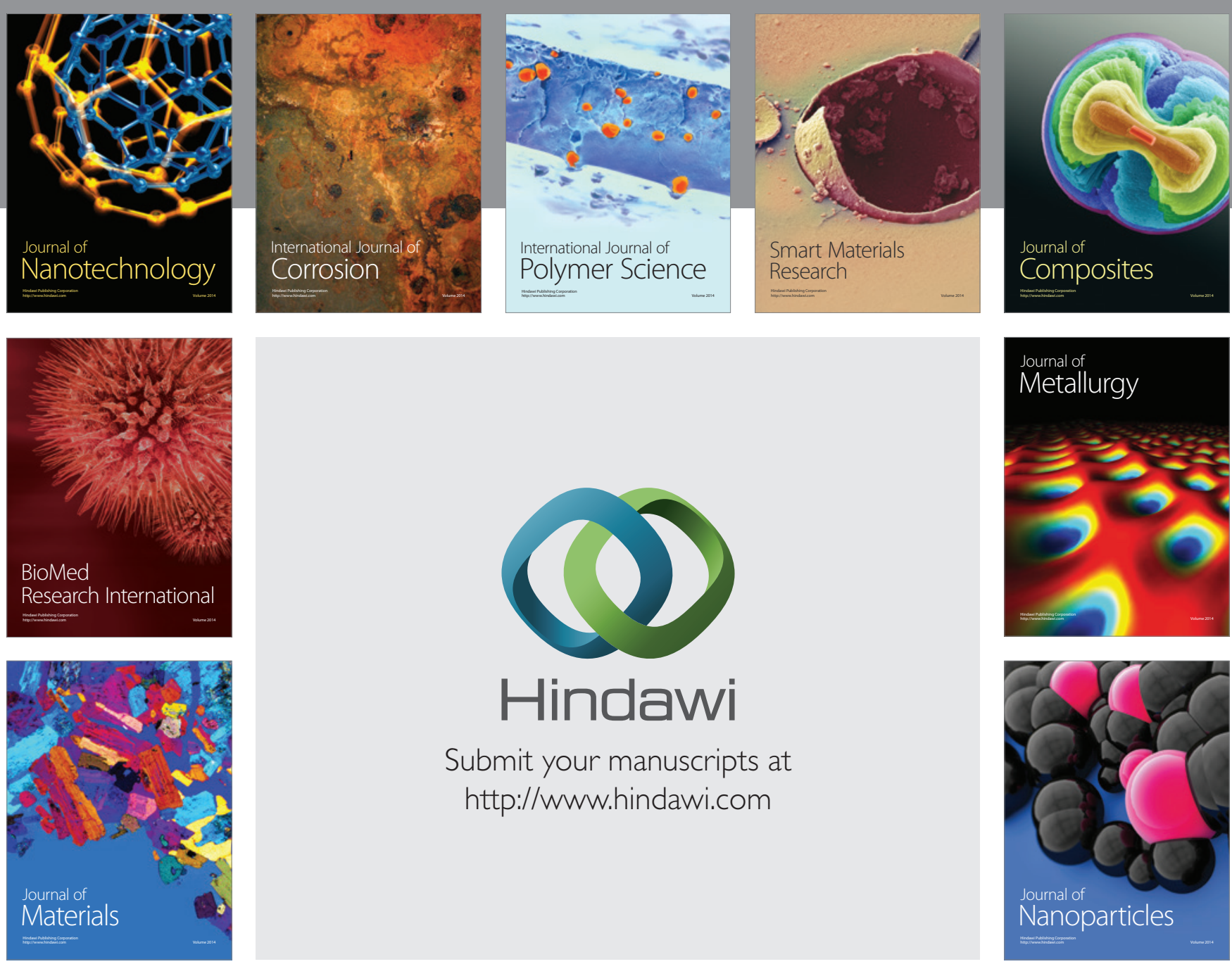

Submit your manuscripts at http://www.hindawi.com
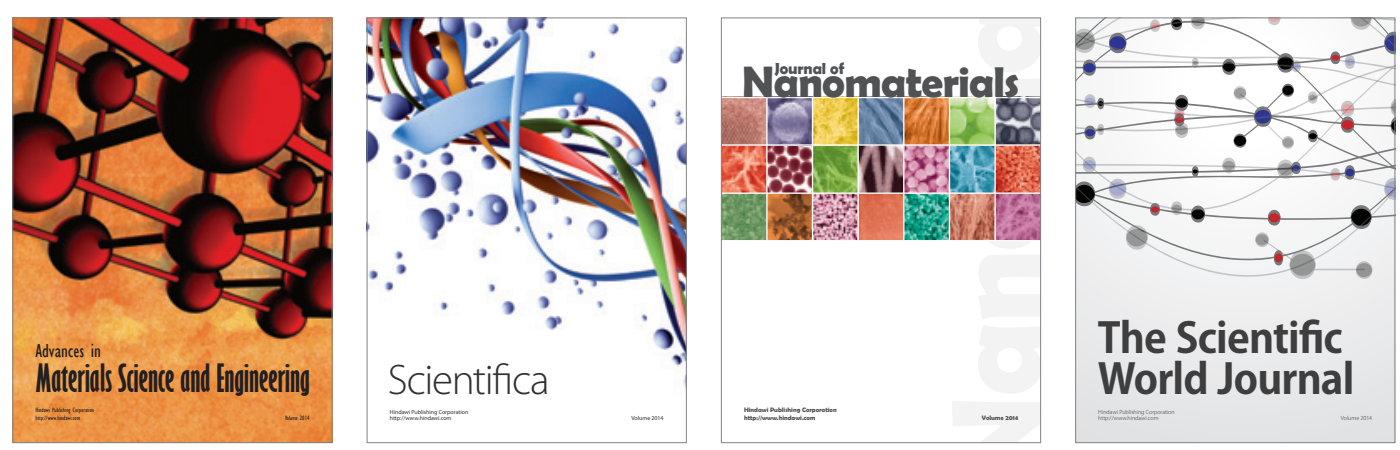

\section{The Scientific World Journal}
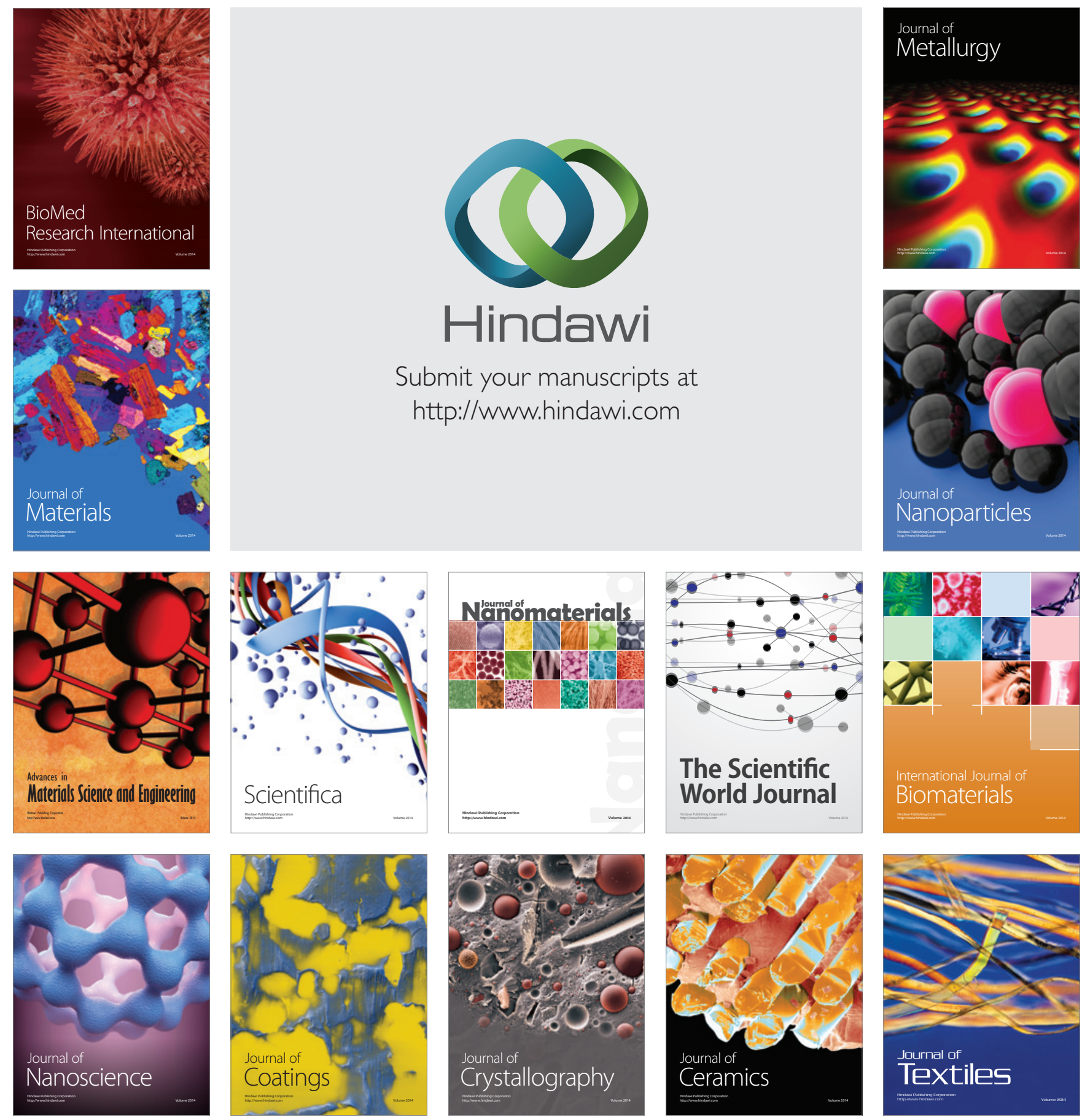